\title{
La vacuna cuadrivalente contra el HPV fue efectiva en la reducción de las lesiones cervicales
}

Quadrivalent HPV vaccine was effective in reducing cervical lesions

Crowe E. y col. BMJ 2014; 348: 1-10.

\section{Objetivos}

Evaluar la efectividad de la vacuna contra el virus del papiloma humano (en inglés HPV) cuadrivalente contra las lesiones cervicales en los cuatros años siguientes a la aplicación del programa nacional de vacunación en Australia.

\section{Diseño, lugar y participantes}

Estudio de casos y controles realizado en Queensland, Australia, a partir de los registros poblacionales de vacunación y de los resultados citológicos e histológicos. Fueron incluidas mujeres de 12 a 26 años candidatas a la vacunación y que se habían atendido para su primer estudio citológico entre 2007 y 2011. Fueron definidos dos grupos de casos y un grupo control: 1) lesiones de alto grado confirmadas por histología; 2) otras lesiones citológicas o histológicas; 3) citología normal.

\section{Principales medidas}

Se realizó análisis estratificado en cuatro grupos etarios (11 a 14 años, 15 a 18, 19 a 22 y 23 a 27 años de edad) ajustado por tiempo de seguimiento, año de nacimiento, nivel socioeconómico y lejanía al centro efector de salud. Se estimó el número de mujeres que sería necesario vacunar para prevenir que una de ellas desarrolle una lesión cervical y la efectividad de cada dosis de vacuna.

El análisis primario comprendió a las mujeres cuyo primer PAP definió su condición de caso o control.

\section{Resultados}

Los principales resultados se describen en la tabla 1.

Tabla 1: efectividad de la vacuna cuadrivalente para la prevención de lesiones de alto grado según el número de dosis recibidas.

\begin{tabular}{c|c|c|c}
\hline Nro. de dosis & Controles & Lesiones de alto grado & OR ajustado \\
\hline 0 & $53032(55 \%)$ & $729(68,7 \%)$ & 1 \\
\hline 1 & $9535(9,9 \%)$ & $114(10,7 \%)$ & $0,95(0,77$ a 1,16$)$ \\
\hline 2 & $10850(11,3 \%)$ & $100(9,4 \%)$ & $0,79(0,64 \mathrm{a} 0,98)$ \\
\hline 3 & $22987(23,8 \%)$ & $119(11,2 \%)$ & $0,54(0,43 \mathrm{a} 0,67)$ \\
\hline
\end{tabular}

La efectividad de dos dosis para la prevención de lesiones de alto grado fue $21 \%$ y la de tres dosis, $46 \%$ (NNT: 125). Se observaron similares tendencias para lesiones más diferenciadas (de menor grado).

\section{Conclusiones}

Tanto el esquema completo como la vacunación parcial con dos dosis proveen protección contra las lesiones de alto grado confirmadas por histología.

Fuente de financiamiento: Universidad de Queensland y otras becas. Conflictos de intereses: no referidos

\section{Comentario}

Existen dos vacunas destinadas a distintos serotipos del HPV: la vacuna cuadrivalente $(11,6,18,16)$ y la bivalente $(16,18)$. Distintos ECCA han documentado la efectividad de ambas para la reducción de las lesiones producidas por dichos serotipos de HPV ${ }^{1-4}$, tanto lesiones cervicales y vulvovaginales, como condilomas genitales en ambos sexos ${ }^{1-2}$.

Si bien existe buena evidencia que demuestra la efectividad de la vacuna, poco se sabe sobre su impacto en la población general. Este estudio poblacional realizado en Queensland a partir del programa nacional de vacunación y del programa extendido de vacunación con la vacuna cuadrivalente, ha documentado asociación inversa (efecto preventivo) entre haber sido va'cunada y el desarrollo de lesiones cervicales de alto grado. Cabe mencionar que pudo observarse un efecto "dosis- respuesta" (a mayor cantidad de dosis recibida, más fuerte fue la asociación inversa), lo que agrega robustez a sus resultados.

\section{Conclusiones del comentador}

Si bien este trabajo avala la efectividad de la vacuna cuadrivalente en la reducción de lesiones cervicales, es importante remarcar que no evalúa su impacto en la morbimortalidad del cáncer de cuello uterino ni los costos de la implementación de este tipo de programa de vacunación. Por eso, si bien consideramos alentadores estos resultados, resaltamos la importancia de continuar implementando los programas de rastreo de cáncer de cérvix con Papanicolau.

Natividad Burdisso [ Servicio de Medicina Familiar y Comunitaria del Hospital Italiano de Buenos Aires. natividad.burdisso@hiba.org.ar ]

Burdisso N. La vacuna cuadrivalente contra el HPV fue efectiva en la reducción de las lesiones cervicales. Evid Act Pract Ambul. 2014. 17(4). Oct-Dic 124. Comentado de: Crowe E y col. Effectiveness of quadrivalent human papillomavirus vaccine for the prevention of cervical abnormalities: case control study nested within a population based screening programme in Australia. BMJ 2014; 348:1-10. PMID: 24594809..

\section{Referencias}

1. Garland S y col. Quadrivalent vaccine against human papillomavirus to prevent anogenital diseases. N Engl J Med 2007; 356: $1928-43$.

2. FUTURE II Study Group. Quadrivalent vaccine against human papillomavirus to prevent high-grade cervical lesions. N Engl J Med 2007;356:1915-27.

3. Ault K. Effect of prophylactic human papillomavirus L1 virus-like-particle vaccine on risk of cervical intraepithelial neoplasia grade 2, grade 3, and adenocarcinoma in situ: a combined analysis of four randomised clinical trials. Lancet 2007;369:1861-8.

4. Paavonen $\mathrm{J}$ y col. Efficacy of a prophylactic adjuvanted bivalent $\mathrm{L} 1$ virus-like-particle vaccine against infection with human papillomavirus types 16 and 18 in young women: an interim analysis of a phase III double-blind, randomised controlled trial. Lancet 2007; 369: 2161-70. 